\title{
OPEN The novel method to reduce the silica content in lignin recovered from black liquor originating from rice straw
}

\author{
Nghi H. Do ${ }^{1}$, Hieu H. Pham ${ }^{2,3}$, Tan M. Le ${ }^{2,3}$, Jeroen Lauwaert ${ }^{4}$, Ludo Diels ${ }^{5,6}$,
} An Verberckmoes ${ }^{4}$, Nga H. N. Do ${ }^{2,3}$, Viet T. Tran ${ }^{2,3}$ \& Phung K. Le ${ }^{2,3 凶}$

Difficulties in the production of lignin from rice straw because of high silica content in the recovered lignin reduce its recovery yield and applications as bio-fuel and aromatic chemicals. Therefore, the objective of this study is to develop a novel method to reduce the silica content in lignin from rice straw more effectively and selectively. The method is established by monitoring the precipitation behavior as well as the chemical structure of precipitate by single-stage acidification at different $\mathrm{pH}$ values of black liquor collected from the alkaline treatment of rice straw. The result illustrates the significant influence of $\mathrm{pH}$ on the physical and chemical properties of the precipitate and the supernatant. The simple two-step acidification of the black liquor at pilot-scale by sulfuric acid $20 \mathrm{w} / \mathrm{v} \%$ is applied to recover lignin at $\mathrm{pH} 9$ and $\mathrm{pH} 3$ and gives a percentage of silica removal as high as $94.38 \%$. Following the developed process, the high-quality lignin could be produced from abundant rice straw at the industrial-scale.

In recent years, the utilization of lignocellulosic biomass as a renewable source for energy and chemical platforms has been investigated by scientists all over the world ${ }^{1}$. Lignin is one of the most potential renewable and sustainable energy resource which is present in a huge amount of agricultural waste such as maize, rice straw, corn stover, sugarcane bagasse, etc. ${ }^{2,3}$. Amongst them, rice straw accounts for the highest proportion of nearly 50 million tons generated annually in Vietnam, especially in the Mekong delta. However, currently, most of the rice straw is burned resulting in huge emissions of harmful gasses such as $\mathrm{NO}_{x}, \mathrm{CO}, \mathrm{CO}_{2}$. Therefore, lignin recovery from rice straw not only prepares a high calorific bio-fuel but also reduces their negative impacts on the environment ${ }^{4-6}$.

The biomass component in rice straw is mainly composed of cellulose, hemicellulose, and lignin which are associated together to form a highly rigid network. Cellulose and hemicellulose are both carbohydrates, while the main building blocks of the lignin structure are phenolic monomers, the so called monolignols ${ }^{7,8}$. These monolignols created the potential of lignin in aromatic compounds production or even biofuel. Additionally, rice straw contains a significant amount of silica, which originates from the soil and enters the roots of the rice plant as mono silicic acid, $\mathrm{Si}(\mathrm{OH})_{4}$. Evaporation and transpiration of water in the plant condense the monomeric $\mathrm{Si}(\mathrm{OH})_{4}$ species to their saturation point, thus leading to the polymerization into insoluble polysilicon acid ${ }^{9,10}$. Furthermore, the appearance of linkages among components was also confirmed. Lignin associates with polysaccharides, especially hemicellulose, via covalent bonds to form lignin-carbohydrate complexes. Likewise, silica is hypothesized to have interaction with cellulose and lignin ${ }^{11,12}$. The recalcitrant structure of lignocellulosic biomass inhibits bio-refineries such as the fermentation of cellulose for bioethanol, conversion of lignin into value-added chemicals. A lot of silica reduction methods were released but some require harsh conditions or special equipment and others are not efficient ${ }^{11,13,14}$. Moreover, there are several desilication methods conducted

${ }^{1}$ Institute of Natural Products Chemistry - Vietnam Academy of Science and Technology, 18 Hoang Quoc Viet, Hanoi, Vietnam. ${ }^{2}$ Refinery and Petrochemicals Technology Research Center (RPTC), Ho Chi Minh City University of Technology (HCMUT), 268 Ly Thuong Kiet Street, Ho Chi Minh City, Vietnam. ${ }^{3}$ Vietnam National University Ho Chi Minh City (VNU-HCM), Linh Trung Ward, Thu Duc District, Ho Chi Minh City, Vietnam. ${ }^{4}$ Industrial Catalysis and Adsorption Technology (INCAT), Department of Materials, Textiles and Chemical Engineering (MaTCh), Faculty of Engineering and Architecture, Ghent University, Valentin Vaerwyckweg 1, 9000 Ghent, Belgium. ${ }^{5}$ Institute of Environment and Sustainable Development (IMDO), University Antwerp, Groenenborgerlaan 171, 2020 Antwerp, Belgium. ${ }^{6}$ Flemish Institute for Technological Research (VITO), Boeretang 200, 2400 Mol, Belgium. ${ }^{\square}$ email: phungle@hcmut.edu.vn 
in mill conditions giving good results, however, this method was not reported about lignin recovery or removing both lignin and silica for gaining cellulose and hemicellulose $e^{9,15,16}$.

The pretreatment process is crucial to disrupting the compact structure in biomass, which enhances the yield and success of potential valorization processes. In the case of rice straw, alkaline pretreatment is the outstanding selection for lignin recovery in rice straw since this method is more effective for herbaceous plants than woody plants ${ }^{17}$. During the alkaline pretreatment, lignocellulose is subjected directly to an alkaline solution, which makes the linkages of silica and another component were broken down, and silica was released into an alkaline medium. Moreover, lignin in rice straw and other grass plants possesses a high degree of ester bonds to hemicellulose that is easy to be cleaved by alkaline medium ${ }^{8,18}$. The resulting liquid after separating the pretreated biomass is called "black liquor," which is originally used to define the waste liquor from the kraft pulping process in paper industries. The alkaline black liquor contains mainly dissolved lignin, silica, and a minor proportion of hemicellulose $\mathrm{e}^{19}$. That is ideal for effective fractionation of lignin and carbohydrate components as well as silica recovery ${ }^{8-10}$. Among available alkaline agents, sodium hydroxide provides the highest yield of delignification ${ }^{20}$. Moreover, the alkaline pretreatment process is a popular method in the bioethanol production industry, so this method would be suitable for upgrading the bioethanol production technique, while considering about economy, sodium hydroxide is a popular chemical and cheaper than potassium hydroxide or another alkaline. In order to recover lignin and silica from black liquor, Kihlman et al. listed three main methods: acidification, ultrafiltration, and electrolysis ${ }^{21}$. Among these, the usage of acid to precipitate lignin have been dominated the others ${ }^{22}$. Minu et al. have analyzed the effects of mineral acids on lignin from rice straw, while Domínguez-Robles et al. proceeded with these studies on wheat straw ${ }^{8}$. Phosphoric acid offers the highest yield of lignin precipitation but requires a high concentration to reach $\mathrm{pH}$ values lower than $4^{22}$. Hydrochloric acid ( $\left.\mathrm{HCl}\right)$ is frequently used in a lab-scale experiment with black liquor obtained from grass plants ${ }^{23-26}$. However, $\mathrm{HCl}$ causes corrosion to stainless steel, thus limiting its application in large-scale operation ${ }^{22}$. Under the consideration of economic aspects and feasibility to apply to industrial production, sulfuric is the acid of choice with a reasonable high yield of lignin recovery ${ }^{27,28}$. Likewise, $\mathrm{HCl}$ and nitric acid $\left(\mathrm{HNO}_{3}\right)$ had lower efficiency compared to sulfuric acid $\left(\mathrm{H}_{2} \mathrm{SO}_{4}\right)^{8}$.

The objective of this study is to develop a novel method to reduce the silica content in lignin from rice straw more effectively and selectively. Rice straw was pretreated with an alkaline solution at a mild condition to collect black liquor. The acidification of black liquor from rice straw was studied in a wide range of $\mathrm{pH}$ to analyze its precipitation behavior, which has not been reported in any available articles. Precipitates at each $\mathrm{pH}$ were analyzed, i.e. their physical properties and chemical structure were analyzed to determine the $\mathrm{pH}$ value for the recovery of lignin and silica. The concentration of $\mathrm{NaOH}$ was also determined to find the appropriate process for silica reduction and recovery high purity lignin, which can be applied in large scale operation or integration with carbohydrates-oriented processes such as bioethanol production. The characterization of the resulting products was carried out by Fourier-transform infrared spectroscopy (FT-IR), X-ray powder diffraction (XRD), and Thermogravimetric analysis (TGA) to elucidate the chemical structure.

\section{Materials and methods}

Materials. Rice straw was collected from $\mathrm{Cu}$ Chi District, Ho Chi Minh City, Vietnam. The paddy straw was thoroughly rinsed and air-dried under the sunlight until the moisture content of below 15\% before being pulverized into pieces of $0.5-2 \mathrm{~mm}$ in length and stored in closed bags. The amount of dry matter in rice straw was determined using Sartorius moisture analyzer MA37. The lignin, hemicellulose, and cellulose content of the dry matter were characterized using the method of Nation Renewable Energy Laboratory (NREL) with a report number of TP-510-42618 ${ }^{29}$. Sodium hydroxide $(\mathrm{NaOH})$ and sulfuric acid $\left(\mathrm{H}_{2} \mathrm{SO}_{4}\right)$ in reagent grade were purchased from Merck. All solutions are prepared in distilled water.

Pretreatment of rice straw. This pretreatment process was carried out at atmospheric pressure. $300 \mathrm{~g}$ rice straw was mixed in a $10 \mathrm{~L}$ boiler with $4.5 \mathrm{~L} \mathrm{NaOH} 1 \mathrm{w} / \mathrm{v} \%$, which was heated to $60{ }^{\circ} \mathrm{C}$ in advance. The mixture was simultaneously mixed by agitator $(150 \mathrm{rpm})$ and heated to $90^{\circ} \mathrm{C}$ in $15 \mathrm{~min}$ and maintained in $2 \mathrm{~h}$ at $90^{\circ} \mathrm{C}$. After pretreatment, the mixture was cooled down to $40^{\circ} \mathrm{C}$, followed by vacuum filtration to remove residues. The volume of obtained liquid, i.e., the black liquor, was about $4.3 \mathrm{~L}$ with a $\mathrm{pH}$ value of 12.4 . The volume loss of the obtained liquid is mainly due to the efficiency of the process of filtration of rice straws residue to gain black liquor and water evaporation during the mixing step.

Single-step acidification of the black liquor. The single-stage acidification was conducted to demonstrate the precipitation behavior of the black liquor. Ten samples containing $200 \mathrm{~mL}$ black liquor were adjusted with diluted $\mathrm{H}_{2} \mathrm{SO}_{4} 20 \mathrm{w} / \mathrm{v} \%$ to reach the $\mathrm{pH}$ value ranging from 10 to 1 . After the acidification finishes, these samples were left $24 \mathrm{~h}$ for aggregation and sedimentation. Each settled mixture was then filtered, and the precipitate was thoroughly washed with deionized water before being dried at $90{ }^{\circ} \mathrm{C}$ until a constant mass of solid was obtained. The obtained precipitate was then ground by an agate mortar and pestle. Those treated samples were analyzed to evaluate the effect of $\mathrm{pH}$ conditions on the precipitation and select an appropriate condition for two-stage acidification.

Two-step acidification of the black liquor. The black liquor was acidified to a $\mathrm{pH}$ value of 3 by $\mathrm{H}_{2} \mathrm{SO}_{4}$ $20 \mathrm{w} / \mathrm{v} \%$ with two-step adjustments at $\mathrm{pH} 9$ and 3. First, the black liquor had a $\mathrm{pH}$ value adjusted to a $\mathrm{pH}$ value of 9 and was then left $36 \mathrm{~h}$ for silica precipitation. The silica gel was then separated from the liquor by vacuum filtration. Finally, the filtrate was diluted with the low concentrated $\mathrm{H}_{2} \mathrm{SO}_{4} 20 \mathrm{w} / \mathrm{v} \%$ to recover lignin at $\mathrm{pH} 3$. 


\begin{tabular}{|l|l|l|l|l|l|}
\hline & Cellulose (wt\%) & Hemicellulose (wt\%) & Lignin (wt\%) & Ash (wt\%) & Dry matter (wt\%) \\
\hline Rice straw & $45.70 \pm 0.16$ & $22.45 \pm 0.15$ & $19.60 \pm 0.18$ & $12.25 \pm 0.15$ & $84.73 \pm 0.53$ \\
\hline Black liquor & $11.85 \pm 0.37$ & $11.20 \pm 0.25$ & $51.81 \pm 0.35$ & $25.14 \pm 0.22$ & $3.21 \pm 0.07$ \\
\hline
\end{tabular}

Table 1. The composition of rice straw and black liquor.

Elucidation of the effect of sodium hydroxide on lignin obtained from the two-step acidification process. The experiment was conducted to find the appropriate $\mathrm{NaOH}$ concentration for the recovery of high purity lignin. The black liquor collected from alkaline pretreatment of rice straw by $\mathrm{NaOH}$ with various concentrations $(0.5 ; 1 ; 2 ; 4 \mathrm{w} / \mathrm{v} \%)$ was two-step acidified. The flow chart of the process to recover lignin from rice straw is shown in Supplemental Fig. S1. The purity and recovery yield of the obtained lignin at different experimental conditions was determined. Each experiment was repeated three times and the average value was calculated.

Analysis methods. The content of ash and non-ash of the obtained precipitations were determined by treating samples at $900 \pm 25^{\circ} \mathrm{C}$ for $6 \mathrm{~h}$ in Nabertherm muffle furnace model LT3/11, therein, the non-ash content was calculated based on the weight difference after calcining. Fourier-transform infrared spectroscopy (FT-IR) spectra of the samples, ranging from 400 to $4000 \mathrm{~cm}^{-1}$ with a $4 \mathrm{~cm}^{-1}$ resolution, were acquired on $\mathrm{KBr}$ pellets using a PerkinElmer Frontier IR instrument. X-ray diffraction (XRD) analysis was performed to demonstrate the structure of samples by using Bruker-D8 Model equipment to record the scattering angle (2 $\theta$ ) and its intensity. Operating conditions were from 10 to $80^{\circ}(2 \theta)$ with a step size of $0.019^{\circ}$ and a step time of $43.00 \mathrm{~s}$ at ambient condition. A CuKa Ni-filtered radiation $(\lambda=1.5406 \AA$ ) was applied with a working voltage of $40 \mathrm{kV}$. The TGA results were investigated using Linseis TGA PT 1600 . The sample was heated from room temperature to $800{ }^{\circ} \mathrm{C}$ with a heating rate of $20^{\circ} \mathrm{C} / \mathrm{min}$ in argon.

The $\mathrm{pH}$ of the black liquors was determined by Thermo Scientific Expert $\mathrm{pH}$ meter. The composition of the obtained precipitates, i.e., ash and lignin content was determined by using the NREL/TP-510-42618 method, i.e., by precipitation via two-step hydrolysis using sulfuric acid solution ${ }^{29}$.

The yield of recovered lignin from rice straw was calculated by the equation:

$$
\% \text { Yield }=\frac{m_{\text {rawlignin }} \times p}{m_{\text {totallignin }}}
$$

where: $m_{\text {rawlignin }}(\mathrm{g})$ is the mass of obtained lignin at $\mathrm{pH} 3 . \mathrm{p}(\%)$ is the purity of obtained lignin at $\mathrm{pH} 3 . m_{\text {totallignin }}$ $(\mathrm{g})$ is the total lignin content in rice straw.

\section{Results and discussion}

The composition of rice straw. The composition of dry matter in rice straw is determined and the result is shown in Table 1 . The rice straw in Vietnam has $50 \mathrm{wt} \%$ of cellulose, $22.45 \mathrm{wt} \%$ of hemicellulose, and $19.6 \mathrm{wt} \%$ of lignin. Meanwhile, the ash percentage of $12.25 \mathrm{wt} \%$ represents the silica content in rice straw because the silica content of Vietnam rice straw ash was as high as $80 \mathrm{wt} \%{ }^{30,31}$. The pretreatment process successfully dissolves silica and lignin in an alkaline solution with the percentage of lignin and ash (silica) in the black liquor increases up to $51.81 \%$ and $25.14 \%$, respectively, thus lignin and silica components can be isolated from the liquor.

The precipitation behavior at different $\mathrm{pH}$ values. The precipitation behavior in acidified black liquors from $\mathrm{pH} 10$ to 1 was described through the physical aspect, weight, and ash (silica) content of the precipitates. The analytical results at each stage of acidification are shown in Fig. 1 indicated the trend of precipitation in black liquor.

As can be seen, the total mass of the precipitate witnesses a gradual increase with decreasing $\mathrm{pH}$ value from 10 to 6 and reaches a peak of $2.89 \mathrm{~g}$ at $\mathrm{pH}$ 5. When the $\mathrm{pH}$ value of the black liquor decreases from 10 to 8 , the amount of ash climbs marginally to a peak of approximately $80 \%$ at $\mathrm{pH} 8$ and keeps stable until $\mathrm{pH}$ 5. According to Aujla et al. and Inglesby et al., silica in rice straw dissolved in the alkaline medium is in the form of sodium silicate at $\mathrm{pH} 10$ and becomes silicic acid when decreasing $\mathrm{pH}$ to lower than 10, explaining the gel formation and the appearance of precipitation as seen from Fig. $2 \mathrm{a}^{32}$. Zaky et al. proposed two chemical equations to clarify the dependence of silica dissolution Eq. (1) and precipitation Eq. (2) on pH value ${ }^{33}$ :

$$
\begin{gathered}
\mathrm{SiO}_{2}+2 \mathrm{NaOH} \rightarrow \mathrm{Na}_{2} \mathrm{SiO}_{3}+\mathrm{H}_{2} \mathrm{O} \\
\mathrm{Na}_{2} \mathrm{SiO}_{3}+\mathrm{H}_{2} \mathrm{SO}_{4} \rightarrow \mathrm{SiO}_{2} \cdot \mathrm{H}_{2} \mathrm{O}+\mathrm{Na}_{2} \mathrm{SO}_{4}
\end{gathered}
$$

Therefore, the presence of dissolved silica (as silicic acid) in black liquor and the formation of sodium silicate precipitation upon acidification is the main reason for the rising and stability of ash content. The precipitate due to gel formation can be ascribed to the formation of the silicic acid hydrate. In the range of $\mathrm{pH} 5-7$, the non-ash content witnesses a significant increase from 20 to $63 \%$. However, the ash content plummets between pH 4 and 3 from $35 \%$ to 16 which is fit to the considerable drop of total precipitate weight. According to Minu et al. the 


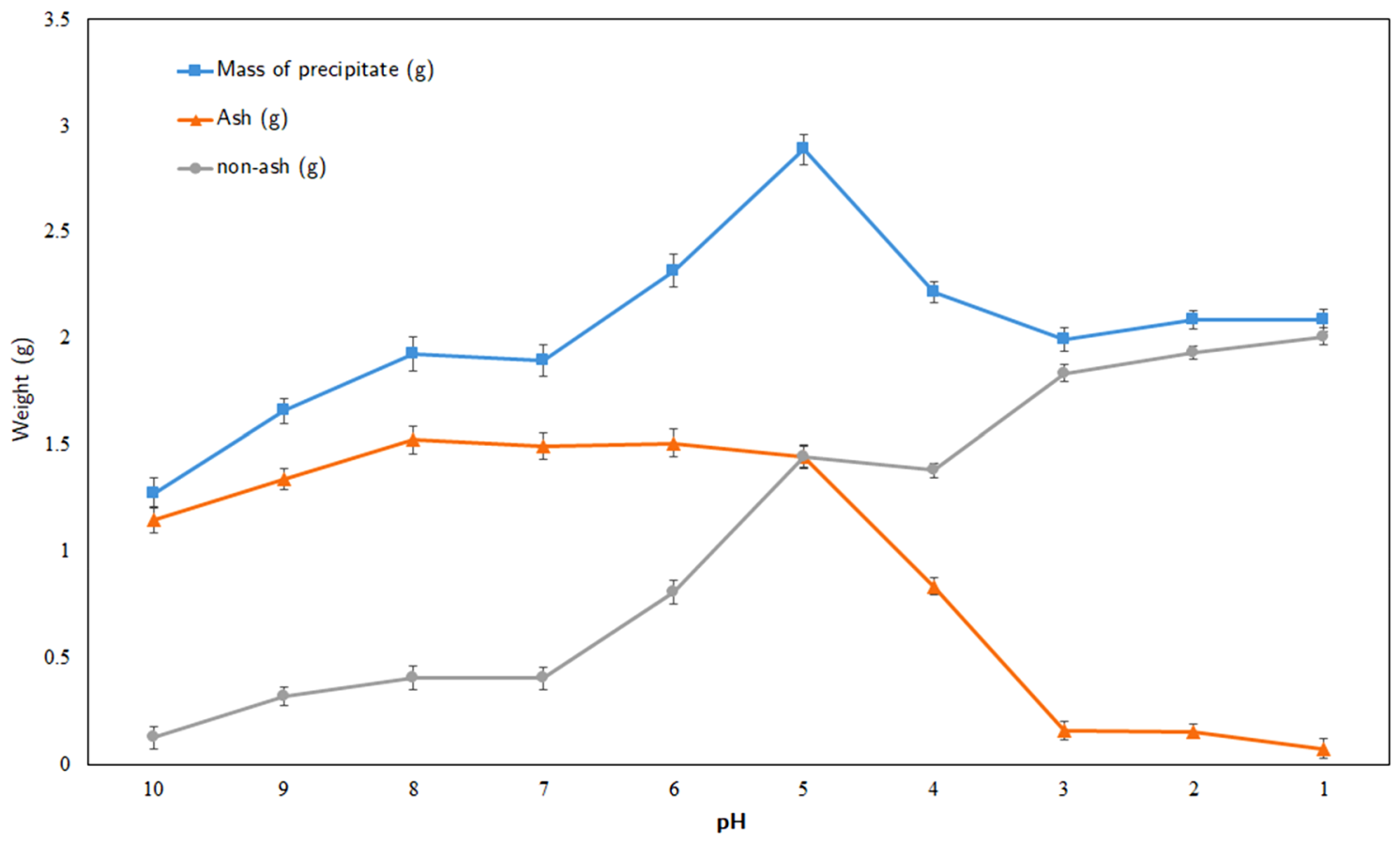

Figure 1. Mass of total precipitate, ash, and non-ash in the black liquors.

acidification of black liquor to $\mathrm{pH}$ lower than 4 leads to the re-dissolution of silica ${ }^{8}$. Hence, at $\mathrm{pH} 3$ and lower, the weight of precipitate remains unchanged due to lignin content. Thus, lignin can be recovered at pH 3 or lower.

The appearance and color change of the precipitate is shown in Fig. 2a. Black liquors treated in a pH range from 10 to 8 are in a state of a dense gel, which could be easily separated by filtration. Substantial precipitation takes place when the $\mathrm{pH}$ of black liquor reaches a value of 10 due to the presence of silicates ${ }^{27}$. The color of the precipitate at $\mathrm{pH} 10$ to 8 is light golden brown while at $\mathrm{pH} 7$ and lower, it noticeably changes to dark brown, which is proportional to the decolorization of the black liquors ${ }^{32}$. The appearance of brown shade in the precipitates is evident from the presence of lignin chromophore ${ }^{34}$. Therefore, the co-precipitation of lignin and silica occurs at $\mathrm{pH} 7$ and lower. The sedimentation of treated liquors occurs instantaneously after the $\mathrm{pH}$ reached 3 or lower values. The brown sediments settle to the bottom of the liquid phase, which takes at least $5 \mathrm{~h}$ to accomplish and the obtained precipitate at this $\mathrm{pH}$ is in a slurry state. This can be explained by the precipitation of lignin at low $\mathrm{pH}$ when lignin acts as a hydrocolloid due to the impacts of protonation of acid groups in lignin structure ${ }^{26}$.

The color alteration of processed liquors at different $\mathrm{pH}$ values is illustrated in Fig. $2 \mathrm{~b}$. The filtrates are remaining dark brown until pH down to 5 before change into opaque reddish-brown. Mussatto et al. reported the color change of the black liquor which originated from brewer's spent grain was observed from $\mathrm{pH} 12$ to $2^{34}$. Garcia et al. demonstrated the transformation of black liquor from the treatment of Miscanthus Sinensis with decreasing $\mathrm{pH}$ from 12 to $1^{27}$. Filtered liquors in both studies, which were collected from the single-step precipitation, turned from dark brown to light brown. Alkaline-soluble derivatives, which are generated during lignin degradation such as quinones, carbonyl groups, carboxylic acids, hydroperoxyl radicals, phenolic hydroxyl groups, are responsible for the dark color of the black liquor ${ }^{35}$.

Clarification of chemical structure. FT-IR analysis. The precipitates from $\mathrm{pH} 10$ to 1 were analyzed using FTIR in the $4000-400 \mathrm{~cm}^{-1}$ region and shown in Fig. 3a,b. Based on the FTIR spectroscopy band assignments of the sample in Table S2, the spectra of all precipitates obtained at $\mathrm{pH}$ values ranging from 10 to 1 exhibit most of the lignin and silica bands (Table S2). In particular, the intensive bands between 3000 and $3500 \mathrm{~cm}^{-1}$ are assigned to $\mathrm{OH}$ stretching vibrations. The lignin bands are present around $1510 \mathrm{~cm}^{-1}$ and $1605 \mathrm{~cm}^{-1}$ for aromatic skeletal vibration $\left(\mathrm{C}=\mathrm{C}\right.$ ) of lignin (guaiacyl or syringyl) whilst the absorption bands around $1604 \mathrm{~cm}^{-1}$ and $1735 \mathrm{~cm}^{-1}$ can be assigned to the $\mathrm{C}=\mathrm{O}$ stretching of lignin ${ }^{36}$. The aromatic ring group is also found in the region of $800 \mathrm{~cm}^{-1}$ and $833 \mathrm{~cm}^{-137}$. The presence of silica is indicated by the $\mathrm{Si}-\mathrm{O}-\mathrm{Si}$ bending region $\left(458-561 \mathrm{~cm}^{-1}\right)$ and the bands from $950-1000 \mathrm{~cm}^{-1}$ of $\mathrm{Si}-\mathrm{O}-\mathrm{Si}$ asymmetric stretching ${ }^{38-40}$.

Figure 3a,b also illustrates that except for the domination of the absorption bands from $3000-3500 \mathrm{~cm}^{-1}$, the spectra of the precipitates from $\mathrm{pH} 10$ to 8 are significantly affected by silica bands. However, the peak of silica decreases from $\mathrm{pH} 7$ steadily (Fig. 3a) and from $\mathrm{pH} 3$ to 1 (Fig. 3b), the effect of silica bands is negligible, whereas the lignin bands are more pronounced in the spectra of precipitates from $\mathrm{pH} 3-1$, which also supports the assumption about the recovery of lignin at $\mathrm{pH} 3$ with less impurity.

XRD analysis. Figure 3c, 3d show an X-ray powder diffraction pattern of the precipitate from black liquors at several $\mathrm{pH}$ values ${ }^{41}$. In general, the absence of peaks of likely impurities such as sodium sulfate and other salts or 

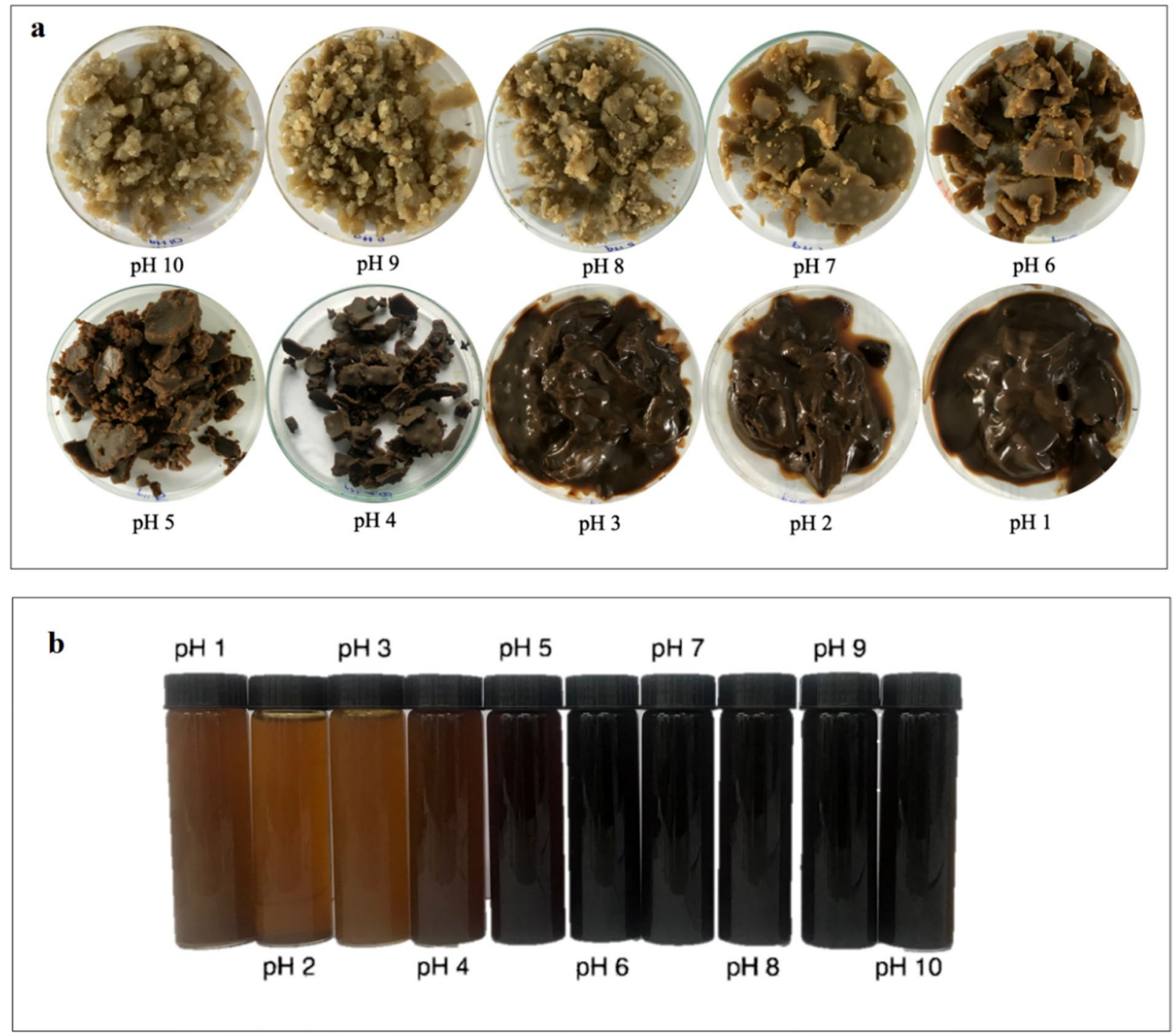

Figure 2. The color variation of the precipitate (a) and the filtrates of black liquors (b) at different $\mathrm{pH}$ values from 1 to 10 .

metals confirms the purity of recovered products ${ }^{42,43}$. The peak between $17^{\circ}$ and $30^{\circ}$ recorded in the precipitate from $\mathrm{pH} 10$ to $\mathrm{pH} 6$ indicates amorphous silica according to Liu et al. and Tinio et al. ${ }^{44,45}$. Together with the featureless diffractograms, the appearance of a diffuse maximum at $22.5^{\circ}$ indicates the amorphous nature of silica existing in the recovered precipitates in this range of $\mathrm{pH}^{46,47}$.

The width of the peak of products at $\mathrm{pH} 5$ and $\mathrm{pH} 4$ is broader from precipitates obtained at higher $\mathrm{pH}$ values indicating a higher amorphous degree (Fig. 3c,d). This might be relevant to the strong alternation in the ash and organic contents in the precipitate at two $\mathrm{pH}$ levels. The similar XRD patterns of products precipitating at $\mathrm{pH}$ lower than 3 are illustrated by a broadening of the peaks between $10^{\circ}$ and $45^{\circ}(2 \theta)$, which indicates the domination of amorphous structure in precipitates at low $\mathrm{pH}$. Therefore, XRD diffractograms in this study prove the correlation in the distribution of silica and organic compounds in recovered products. Kauldhar et al. claimed that the XRD pattern of standard pure lignin showed a major diffraction peak between $23^{\circ}$ and $32^{\circ}(2 \theta)^{10}$.

TG analysis. The thermogram of recovered products precipitated at basic pH from 10 to 1 is shown in Fig. 4. We obtained four temperature zones, as interpreted in the following. The precipitated products at $\mathrm{pH} 10, \mathrm{pH} 9$, $\mathrm{pH} 8$, and $\mathrm{pH} 7$ witnessed a thermal degradation by about $25 \mathrm{wt} \%$. The second group including profiles of $\mathrm{pH}$ 6 , $\mathrm{pH} 5$, and $\mathrm{pH} 4$, had the total mass loss ranging from $41-53 \%$. The last group, which contains TGA curves of precipitate obtaining at $\mathrm{pH} 3, \mathrm{pH} 2$, and $\mathrm{pH} 1$, experienced about $80 \mathrm{wt} \%$ loss due to thermal degradation.

The first stage occurred below $100{ }^{\circ} \mathrm{C}$ due to the evaporation of physically adsorbed water. The thermogram of precipitates at $\mathrm{pH} 10$ to $\mathrm{pH} 4$ reported the fluctuated mass reduction in the range of $10-14 \mathrm{wt} \%$, while the weight loss of products precipitated at $\mathrm{pH} 3$ and lower decreased to 7\%. The adsorption of water on the surface of $\mathrm{OH}$ groups of silica is responsible for the higher moisture content of recovered products at $\mathrm{pH} 10-4^{10}$.

The second stage was observed around $100^{\circ} \mathrm{C}-260^{\circ} \mathrm{C}$, which indicated the decomposition of polysaccharides, aliphatic alcohols, and acids ${ }^{48}$. At $\mathrm{pH}$ ranging from 10 to 4 , the mass loss was less than $6 \mathrm{wt} \%$, which confirms 

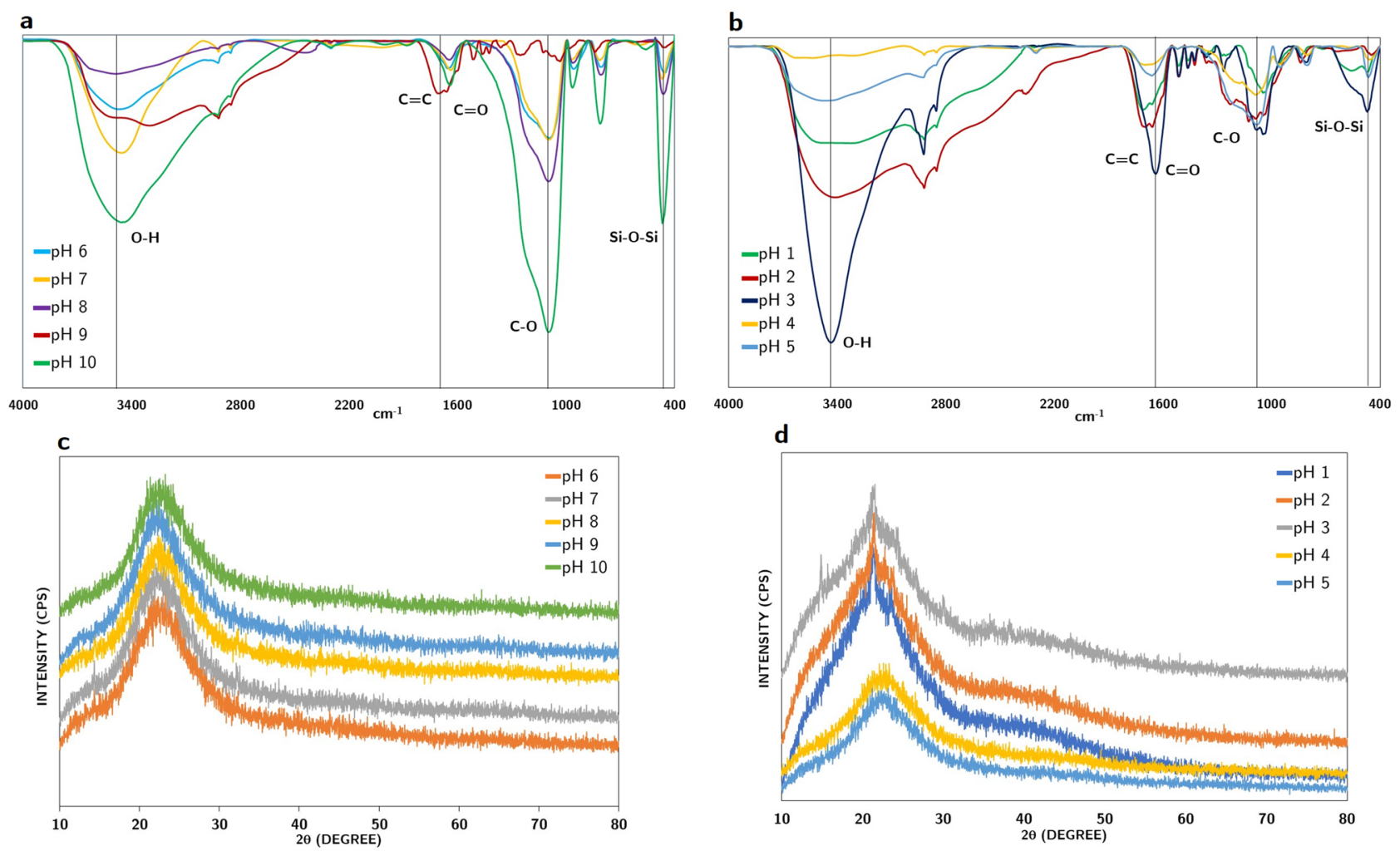

Figure 3. FTIR and XRD spectrums of the precipitate from $\mathrm{pH} 10$ to $\mathrm{pH} 6(\mathbf{a}, \mathbf{c})$ and from $\mathrm{pH} 5$ to $\mathrm{pH} 1(\mathbf{b}, \mathbf{d})$.
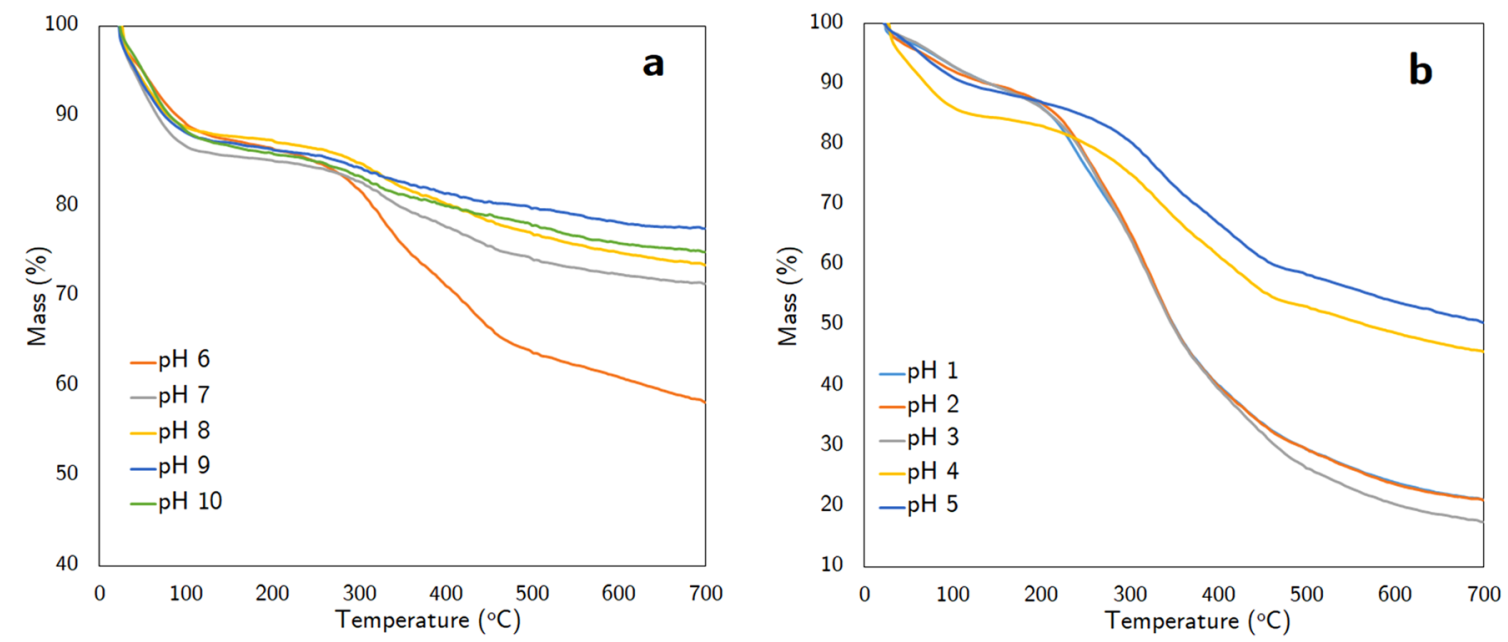

Figure 4. TG analysis of the precipitates from $\mathrm{pH} 10$ to $\mathrm{pH} 5$ (a) and from $\mathrm{pH} 4$ to $\mathrm{pH} 1$ (b).

the negligible presence of non-lignin compounds co-precipitating with silica, whereas $10-14 \%$ of weight loss was reported from samples recovered at $\mathrm{pH} 3$ to $\mathrm{pH}$. The noticeable loss implies the coprecipitation of lignin and hemicellulose, which is evident in the existence of lignin-carbohydrates complexes ${ }^{49}$. Also, organic compounds were likely converted into intermediates, which did not affect the weight reduction ${ }^{42}$.

The increase in thermal degradation occurred mainly in the temperature interval of $260^{\circ} \mathrm{C}-480^{\circ} \mathrm{C}$. From $\mathrm{pH}$ 10 to $\mathrm{pH} 7$, the mass loss is approaching $8 \mathrm{wt} \%$, then jumps to the range of $18-24 \%$ at $\mathrm{pH} 6$ to $\mathrm{pH} 4$. The weight loss reached $50 \mathrm{wt} \%$ at $\mathrm{pH} 3$ and remained the same at $\mathrm{pH} 2$ and $\mathrm{pH} 1$. This third stage included the subsequent transformation of intermediates, which were formed in the second stage, into gaseous components and $\operatorname{tar}^{42}$. The decomposition of lignin happened strongly in this stage. Since lignin consists of aromatic building blocks with diverse branching, the thermal properties of lignin are varied due to the difference in biomass origin ${ }^{10}$.

At the fourth stage over $480{ }^{\circ} \mathrm{C}$, a negligible mass loss of less than $5 \%$ was recorded from thermograms of samples from $\mathrm{pH} 10$ down to $\mathrm{pH}$ 6. The weight loss of samples at $\mathrm{pH} 5$ and $\mathrm{pH} 4$ were $9 \%$. At $\mathrm{pH} 3$ and lower, the thermal degradation of samples rose to $15 \mathrm{wt} \%$. 


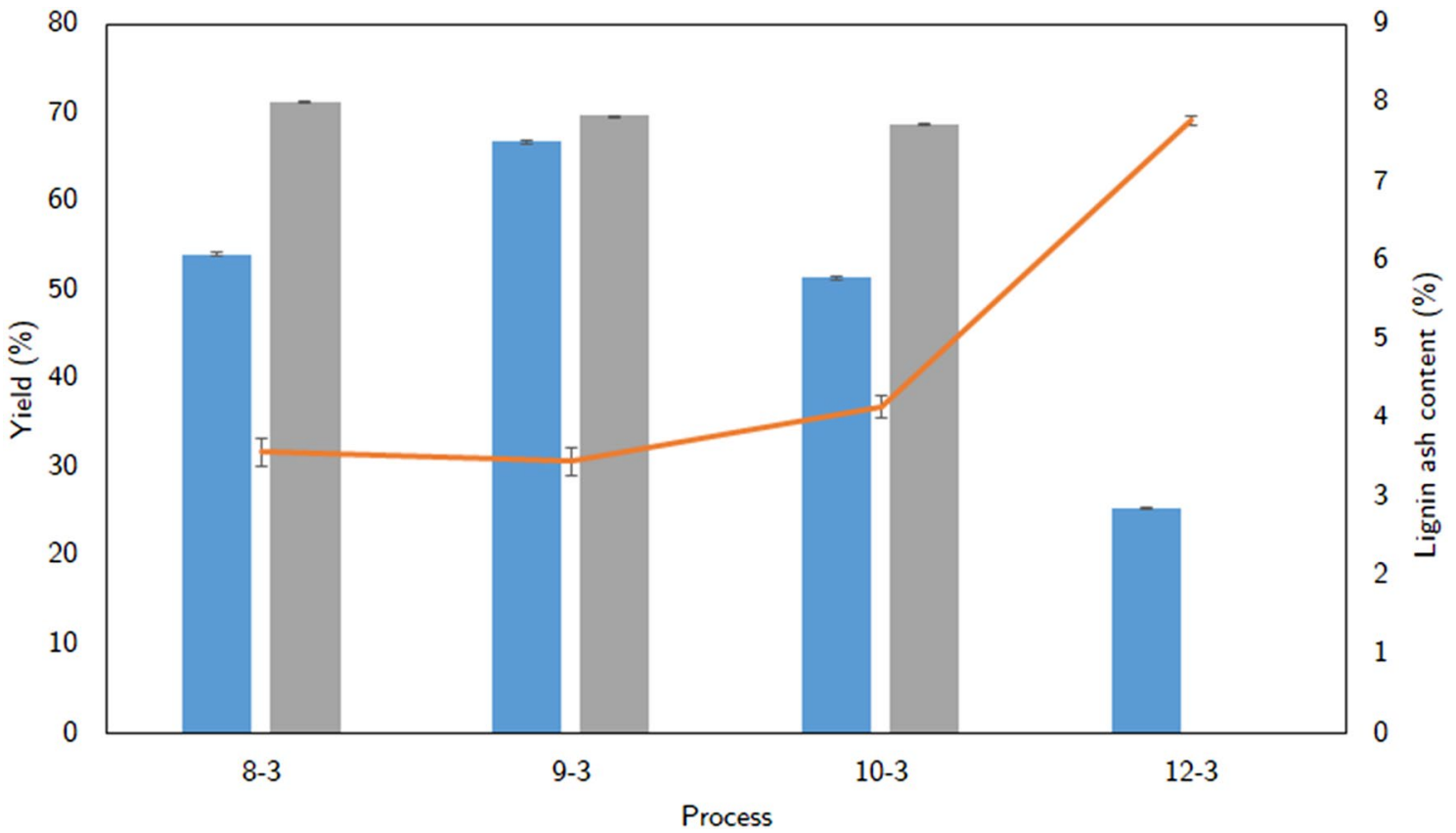

Lignin recovery yield _ Silica recovery yield _Lignin ash content

Figure 5. The recovery yield of lignin and silica, the ash content of lignin in difference processes.

In general, the results of all experiments, including FTIR, XRD analysis, and TG analysis, indicated that the lignin and silica precipitates were able to be recovered at acidic $\mathrm{pH}$ value $(\mathrm{pH} 1-3)$ and basic $\mathrm{pH}$ value $(\mathrm{pH}$ $8-10)$, respectively.

Determination of $\mathrm{pH}$ for removing silica content. In order to determine the optimal $\mathrm{pH}$ for removing silica out of black liquor and recovering desilication lignin, the black liquor was adjusted to $\mathrm{pH} 8,9,10$, and then to $\mathrm{pH} 3$ to find out the appropriated $\mathrm{pH}$ value. The results were shown in Fig. 5 indicating the amount of silica obtained at $\mathrm{pH} 8$ is the highest followed by $\mathrm{pH} 9$ and 10 . While the yield of lignin at the 9-3 process is higher than the 8-3 process and the purity of two processes is not significantly different. Therefore, when considering the economy, the 9-3 process is outstanding for desilication lignin production and recovery of silica.

The two-step acidification for recovery lignin with high purity. The target of this process is to obtain pure lignin by removing silica-based components out of the black liquor before recovering lignin. According to the results of all experiments, that process is divided into 2 steps. First-step, black liquor was acidified to $\mathrm{pH}$ 9 to remove silica and the next step is lignin recovery at $\mathrm{pH} 3$. The lignin precipitate from this process will be analyzed to assess the lignin component, the analytical results are shown in Fig. 6. The FTIR spectrum of the precipitate from the two-step process (Fig. 6a) demonstrates that the presence of a special band of lignin is around $1510 \mathrm{~cm}^{-1}$ and $1605 \mathrm{~cm}^{-1}$ for aromatic skeletal vibration $(\mathrm{C}=\mathrm{C})$ of lignin (guaiacyl or syringyl). The effect of the silica band is insignificant because of the absence of silica bands around $458-561 \mathrm{~cm}^{-1}$. However, the XRD analysis results (Fig. 6b) show that there are 2 peaks around $22^{\circ}$. This proves that the extracted lignin is not completely removed from the silica, although the ash content is $3.46 \%$ of total precipitation weight equivalent to $81.11 \%$ silica reduction (Fig. 7). Therefore, the two-steps process could be presumed as a method to obtain pure lignin.

Effect of sodium hydroxide concentration on lignin yield and recovery in the 2-step process towards industrial implementation. However, in order to apply the proposed 2-step lignin and silica recovery process at the industrial scale, it must satisfy in many factors such as economy, efficiency, and safety during implementation. In particular, the concentration of $\mathrm{NaOH}$ is one of the important factors. The higher the $\mathrm{NaOH}$ concentration is used, the higher the safety risks that take place in the mixing or operation process. Moreover, the operating equipment should have special requirements for high corrosion resistance. Therefore, the experiment is conducted to find the appropriate $\mathrm{NaOH}$ concentration for the recovery of lignin from the black liquor by a 2 -step process. The effect of $\mathrm{NaOH}$ concentration on the lignin recovery yield and the purity of lignin is shown in Fig. 7. The result depicts that $\mathrm{NaOH} 1 \mathrm{w} / \mathrm{v} \%$ process had the most potential for recovery lignin with $66.75 \%$ lignin recovery yield followed by $\mathrm{NaOH} 0.5 \mathrm{w} / \mathrm{v} \%$ process with $52.64 \%$ lignin recovery yield, while the silica content of $\mathrm{NaOH} 1 \mathrm{w} / \mathrm{v} \%$ and $\mathrm{NaOH} 2 \mathrm{w} / \mathrm{v} \%$ process is $3.46 \%$ and $3.22 \%$ equivalent to $94.38 \%$ and 99.98\% of removed silica content, respectively. The obtained lignin from the process using $\mathrm{NaOH} 0.5 \mathrm{w} / \mathrm{v} \%$ has the highest purity of $78.91 \%$. The reason is that at high alkaline concentration, the polysaccharides in rice straw were degraded and dissolved which leads to decreasing lignin recovery yields ${ }^{50}$. Therefore, the study suggests 


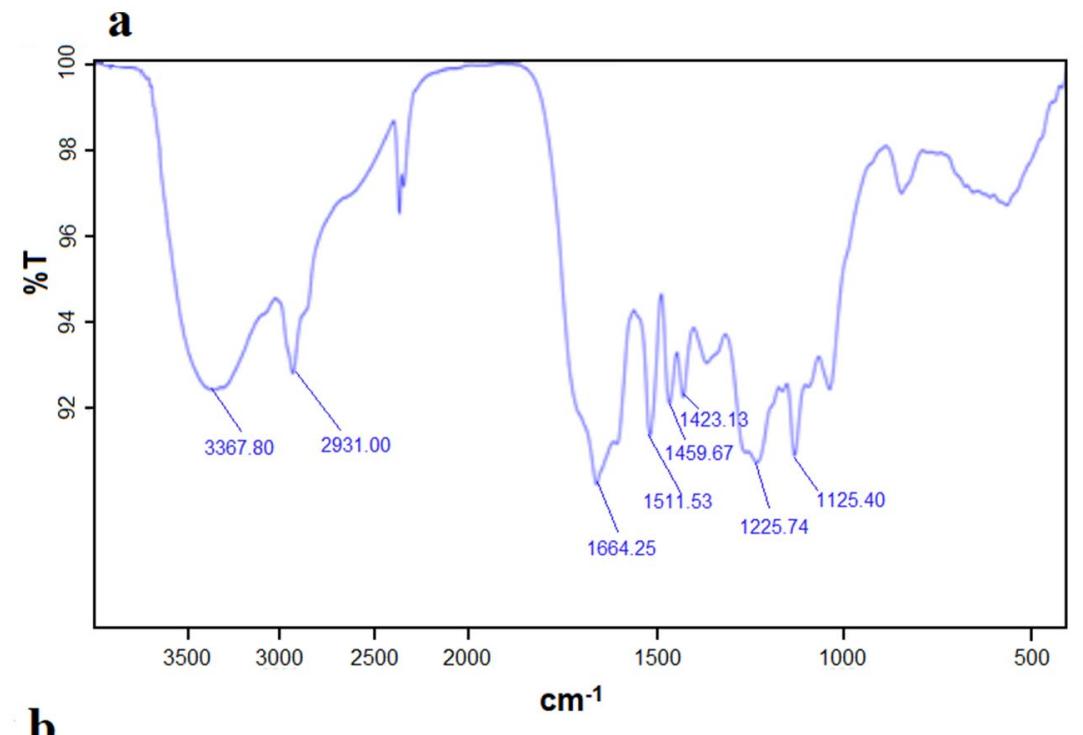

b

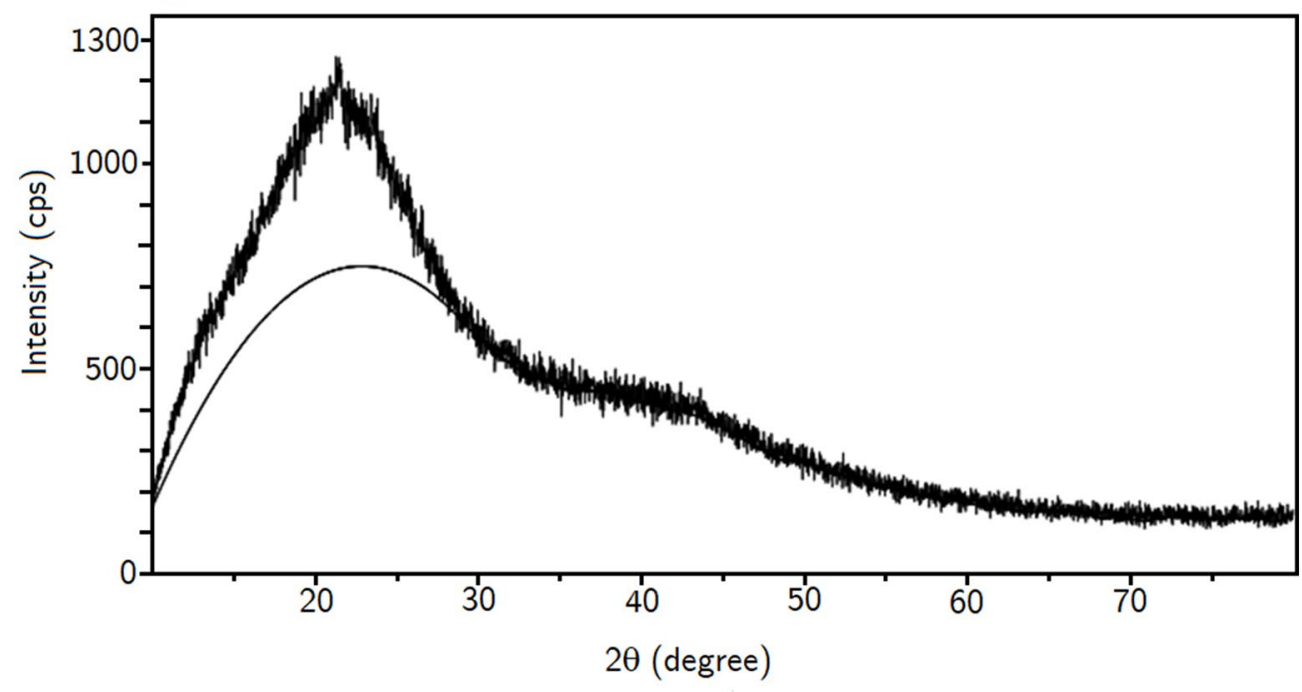

Figure 6. FTIR and XRD spectrums of lignin in a two-steps process.

the process using $\mathrm{NaOH} 1 \mathrm{w} / \mathrm{v} \%$ in the pretreatment process and following the two-step process as shown in Supplemental Fig. S1 because of the silica reduction, lignin recovery yield, and purity.

\section{Conclusions}

The effects of $\mathrm{pH}$ value on the behavior of the precipitates of lignin and silica from the black liquor of rice straw have been comprehensively investigated by step-by-step acidification with dilute $\mathrm{H}_{2} \mathrm{SO}_{4}$. The color of the precipitate changes from golden brown to dark brown with decreasing $\mathrm{pH}$ value, whereas the opposite trend is true for the filtrate. The $\mathrm{pH}$ value of 3 is demonstrated to recover lignin most effectively based on chemical structure analysis, while a $\mathrm{pH}$ range of $10-8$ was demonstrated to remove silica from the black liquor. A two-step acidification process was developed with prior acidification in diluted sulfuric acid to $\mathrm{pH} 9$ and removal of silica, followed by acidification to $\mathrm{pH} 3$ for optimal lignin recovery. These findings are valuable in mass production to identify the lignin recovery in acidification of the black liquor. Moreover, in the view of industrialization, with utilizing low concentration basic chemical as $\mathrm{NaOH} 1 \%$ and $\mathrm{H}_{2} \mathrm{SO}_{4} 20 \%$, this method was not only producing value-add products but also saving energy and lowering the waste to the environment because of its simplicity and efficiency. The precipitate obtained at $\mathrm{pH} 3$ shows the highest lignin purity of $65.74 \%$, the recovery yield of $66.75 \%$, and the silica reduction of $94.38 \%$ by using diluted sodium hydroxide with a low concentration of $1 \mathrm{w} / \mathrm{v} \%$. 


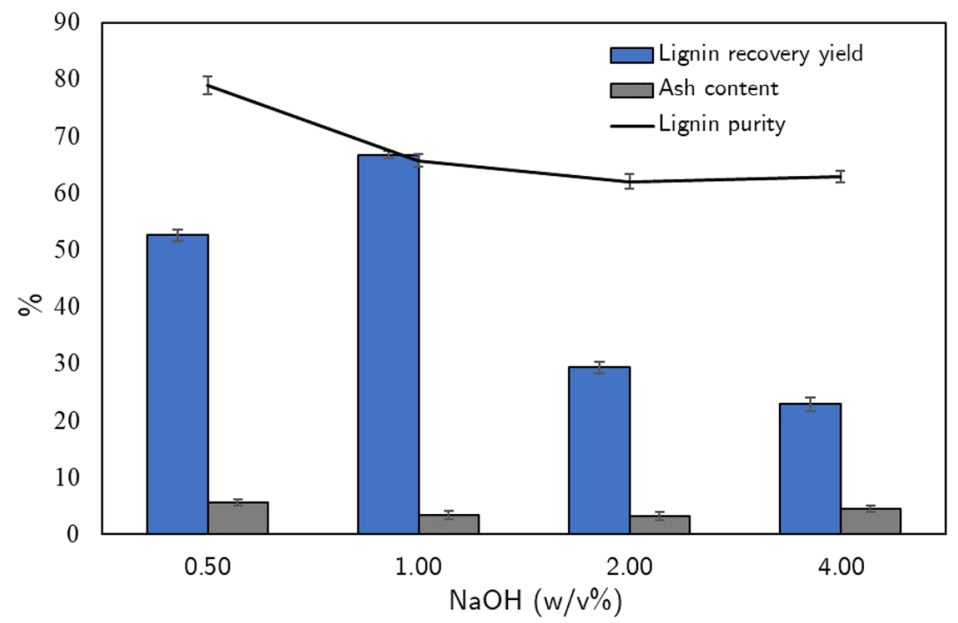

Figure 7. The recovery yield, the purity, and the silica content of lignin in several concentrations of $\mathrm{NaOH}$.

Received: 15 August 2020; Accepted: 17 November 2020

Published online: 04 December 2020

\section{References}

1. Ferro, M. D. et al. Bioethanol production from steam explosion pretreated and alkali extracted Cistus ladanifer (rockrose). Biochem. Eng. J. 104, 98-105 (2015).

2. Oldoni, T. L. C. et al. Chemical characterization and optimization of the extraction process of bioactive compounds from propolis produced by selected bees Apis mellifera. J. Braz. Chem. Soc. 26, 2054-2062 (2015).

3. Prado, R., Erdocia, X. \& Labidi, J. Lignin extraction and purification with ionic liquids. J. Chem. Technol. Biotechnol. 88, 1248-1257 (2013).

4. Diep, N. Q., Sakanishi, K., Nakagoshi, N., Fujimoto, S. \& Minowa, T. Potential for rice straw ethanol production in the Mekong Delta, Vietnam. Renew. Energy 74, 456-463 (2015).

5. Dinh, Vu. N., Thi Tran, H., Bui, N. D., Duc, Vu. C. \& Viet, N. H. Lignin and cellulose extraction from Vietnam's rice straw using ultrasound-assisted alkaline treatment method. Int. J. Polym. Sci. 20, 17. https://doi.org/10.1155/2017/1063695 (2017).

6. Liu, G. \& Bao, J. Maximizing phosphorus and potassium recycling by supplementation of lignin combustion ash from dry biorefining of lignocellulose. Biochem. Eng. J. 144, 104-109 (2019).

7. Schutyser, W. et al. Chemicals from lignin: an interplay of lignocellulose fractionation, depolymerisation, and upgrading. Chem. Soc. Rev. 47, 852-908 (2018).

8. Minu, K., Jiby, K. K. \& Kishore, V. V. N. Isolation and purification of lignin and silica from the black liquor generated during the production of bioethanol from rice straw. Biomass Bioenergy 39, 210-217 (2012).

9. Khaleghian, H., Molaverdi, M. \& Karimi, K. Silica removal from rice straw to improve its hydrolysis and ethanol production. Ind. Eng. Chem. Res. 56, 9793-9798 (2017).

10. Kauldhar, B. S. \& Yadav, S. K. Turning waste to wealth: A direct process for recovery of nano-silica and lignin from paddy straw agro-waste. J. Clean. Prod. 194, 158-166 (2018).

11. Le, D. M., Sørensen, H. R., Knudsen, N. O. \& Meyer, A. S. Implications of silica on biorefineries-interactions with organic material and mineral elements in grasses. Biofuels Bioprod. Biorefin. 9, 109-121 (2015).

12. Cabrera, Y., Cabrera, A., Larsen, F. H. \& Felby, C. Solid-state 29Si NMR and FTIR analyses of lignin-silica coprecipitates. Holzforschung 70, 709-718 (2016).

13. Kaur, K. \& Phutela, U. G. Sodium carbonate pretreatment: an approach towards desilication of paddy straw and enhancement in biogas production. Paddy Water Environ. 14, 113-121 (2016).

14. Chiranjeevi, T. et al. Assisted single-step acid pretreatment process for enhanced delignification of rice straw for bioethanol production. ACS Sustain. Chem. Eng. 6, 8762-8774 (2018).

15. Syazwanee, M. G. M. F., Shaziera, A. G. N., Izzati, M. Z. N. A., Azwady, A. A. N. \& Muskhazli, M. Improvement of delignification, desilication and cellulosic content availability in paddy straw via physico-chemical pretreatments. Annu. Res. Rev. Biol. https:// doi.org/10.9734/ARRB/2018/40947 (2018).

16. Myréen, B. A novel desilication technology could prove a valuable boost for straw pulp mills. Pulp Pap. Asia 10, 107 (2000).

17. Sun, R. Cereal Straw as a Resource for Sustainable Biomaterials and Biofuels: Chemistry, Extractives, Lignins, Hemicelluloses and Cellulose (Elsevier, Amsterdam, 2010).

18. Van Soest, P. J. Rice straw, the role of silica and treatments to improve quality. Anim. Feed Sci. Technol. 130, 137-171 (2006).

19. Bajpai, P. Biermann's Handbook of Pulp and Paper: Volume: Raw Material and Pulp Making (Elsevier, Amsterdam, 2018).

20. Sindhu, R., Pandey, A. \& Binod, P. Alkaline treatment. In Pretreatment of Biomass 51-60 (Elsevier, Amsterdam, 2015).

21. Kihlman, J. The sequential liquid-lignin recovery and purification process: Analysis of integration aspects for a kraft pulp mill. Nord. Pulp Pap. Res. J. 31, 573-582 (2016).

22. Hubbe, M. A., Alén, R., Paleologou, M., Kannangara, M. \& Kihlman, J. Lignin recovery from spent alkaline pulping liquors using acidification, membrane separation, and related processing steps: a review. BioResources 14, 2300-2351 (2019).

23. Yuan, T.-Q., He, J., Xu, F. \& Sun, R.-C. Fractionation and physico-chemical analysis of degraded lignins from the black liquor of Eucalyptus pellita KP-AQ pulping. Polym. Degrad. Stab. 94, 1142-1150 (2009).

24. Zhao, B.-C. et al. Selective precipitation and characterization of lignin-carbohydrate complexes (LCCs) from Eucalyptus. Planta 247, 1077-1087 (2018).

25. Chen, W.-J. et al. Structural features of alkaline dioxane lignin and residual lignin from eucalyptus grandis $\times$ E. Urophylla. J. Agric. Food Chem. 67, 968-974 (2018).

26. Hermiati, E., Risanto, L., Lubis, M. A. R., Laksana, R. P. B. \& Dewi, A. R. Chemical characterization of lignin from kraft pulping black liquor of Acacia mangium. In AIP Conference Proceedings vol. 180320005 (AIP Publishing LLC, 2017). 
27. García, A. et al. Characterization of lignins obtained by selective precipitation. Sep. Purif. Technol. 68, 193-198 (2009).

28. Kim, M., Kim, B.-C., Nam, K. \& Choi, Y. Effect of pretreatment solutions and conditions on decomposition and anaerobic digestion of lignocellulosic biomass in rice straw. Biochem. Eng. J. 140, 108-114 (2018).

29. Sluiter, A. et al. Determination of structural carbohydrates and lignin in biomass. Lab. Anal. Proced. 1617, 1-16 (2008).

30. Van Hung, N. et al. Rice Straw Overview: Availability, Properties, and Management Practices. In Sustainable Rice Straw Management 1-13 (Springer, Cham, 2020).

31. Migo, M. V. P. Optimization and life cycle assessment of the direct combustion of rice straw using a small scale, stationary grate furnace for heat generation. Unpubl. Masters thesis. Univ. Philipp. Los Baños (2019).

32. Inglesby, M. K. et al. Surface characterization of untreated and solvent-extracted rice straw. Colloids Surf. B 43, 83-94 (2005).

33. Zaky, R. R. et al. Preparation of silica nanoparticles from semi-burned rice straw ash. Powder Technol. 185, 31-35 (2008).

34. Mussatto, S. I., Fernandes, M. \& Roberto, I. C. Lignin recovery from brewer's spent grain black liquor. Carbohydr. Polym. 70, 218-223 (2007).

35. Fengel, D. \& Wegener, G. Wood: Chemistry, Ultrastructure, Reactions (Walter de Gruyter, New York, 2011).

36. Esteves, B., Velez Marques, A., Domingos, I. \& Pereira, H. Chemical changes of heat treated pine and eucalypt wood monitored by FTIR. Maderas. Cienc. Tecnol. 15, 245-258 (2013).

37. Li, X., Liu, Y., Hao, J. \& Wang, W. Study of almond shell characteristics. Materials 11, 1782 (2018).

38. Kopani, M., Mikula, M., Kosnac, D., Gregus, J. \& Pincik, E. Morphology and FT IR spectra of porous silicon. J. Electr. Eng. 68, 53-57 (2017).

39. Zemnukhova, L. A., Panasenko, A. E., Artem'yanov, A. P. \& Tsoy, E. A. Dependence of porosity of amorphous silicon dioxide prepared from rice straw on plant variety. BioResources 10, 3713-3723 (2015).

40. Khan, A. S. et al. Vibrational spectroscopy of selective dental restorative materials. Appl. Spectrosc. Rev. 52, 507-540 (2017),

41. Musić, S., Filipović-Vinceković, N. \& Sekovanić, L. Precipitation of amorphous SiO2 particles and their properties. Braz. J. Chem. Eng. 28, 89-94 (2011).

42. Lu, P. \& Hsieh, Y.-L. Highly pure amorphous silica nano-disks from rice straw. Powder Technol. 225, 149-155 (2012).

43. Chen, X., Wang, Z., Fu, Y., Li, Z. \& Qin, M. Specific lignin precipitation for oligosaccharides recovery from hot water wood extract. Bioresour. Technol. 152, 31-37 (2014).

44. Liu, Y. et al. A sustainable route for the preparation of activated carbon and silica from rice husk ash. J. Hazard. Mater. 186, 1314-1319 (2011).

45. Tinio, J. V. G., Simfroso, K. T., Peguit, A. D. M. V. \& Candidato, R. T. Influence of OH- ion concentration on the surface morphology of zno-sio2 nanostructure. J. Nanotechnol. 20, 15. https://doi.org/10.1155/2015/686021 (2015).

46. Liu, Y. et al. Simultaneous preparation of silica and activated carbon from rice husk ash. J. Clean. Prod. 32, 204-209 (2012).

47. Kumagai, S. \& Sasaki, J. Carbon/silica composite fabricated from rice husk by means of binderless hot-pressing. Bioresour. Technol. 100, 3308-3315 (2009).

48. Ramakoti, B. et al. Solvent fractionation of organosolv lignin to improve lignin homogeneity: structural characterization. Bioresour. Technol. Reports 7, 100293 (2019).

49. Toledano, A. et al. Heterogeneously catalysed mild hydrogenolytic depolymerisation of lignin under microwave irradiation with hydrogen-donating solvents. Chem CatChem 5, 977-985 (2013).

50. Kontogianni, N., Barampouti, E. M., Mai, S., Malamis, D. \& Loizidou, M. Effect of alkaline pretreatments on the enzymatic hydrolysis of wheat straw. Environ. Sci. Pollut. Res. 26, 35648-35656 (2019).

\section{Acknowledgements}

This research is funded by Vietnam National Foundation for Science and Technology Development (NAFOSTED) under grant number FWO.104.2017.03. We acknowledge the support of time and facilities from Ho Chi Minh City University of Technology (HCMUT), VNU-HCM for this study.

\section{Author contributions}

N.H.D., H.H.P., T.M.L., performed experimental design and data collection and manuscript revision and funding acquisition and manuscript preparation and data analysis. J. L., L.D., A.V., N.H.N.D. participated in manuscript revision and experimental design and funding acquisition manuscript revision and experimental design and funding acquisition, V.T.T joined in conceived and designed the analysis and anesthesia domain knowledge and manuscript revision, P.K.L. planed and conceived and designed the analysis and anesthesia domain knowledge and manuscript revision and funding acquisition and manuscript reparation.

\section{Competing interests}

The authors declare no competing interests.

\section{Additional information}

Supplementary information is available for this paper at https://doi.org/10.1038/s41598-020-77867-5.

Correspondence and requests for materials should be addressed to P.K.L.

Reprints and permissions information is available at www.nature.com/reprints.

Publisher's note Springer Nature remains neutral with regard to jurisdictional claims in published maps and institutional affiliations.

Open Access This article is licensed under a Creative Commons Attribution 4.0 International License, which permits use, sharing, adaptation, distribution and reproduction in any medium or format, as long as you give appropriate credit to the original author(s) and the source, provide a link to the Creative Commons licence, and indicate if changes were made. The images or other third party material in this article are included in the article's Creative Commons licence, unless indicated otherwise in a credit line to the material. If material is not included in the article's Creative Commons licence and your intended use is not permitted by statutory regulation or exceeds the permitted use, you will need to obtain permission directly from the copyright holder. To view a copy of this licence, visit http://creativecommons.org/licenses/by/4.0/.

(C) The Author(s) 2020, corrected publication 2021 